\title{
Impacts of geographical diversity of ethnic groups on order and security Case study: Islamic Republic of Iran
}

\author{
Seid Mohamad Reza Mahmodpanahi ${ }^{1, *}$, Mohamad Hasan Elahimanesh ${ }^{2}$, \\ Ali Namdar ${ }^{3}$ \\ ${ }^{1}$ Assistant professor, Department of History, Payame Noor University, PO BOX 19395 - 3697 , \\ Tehran, IRAN \\ ${ }^{2}$ Assistant professor, Department of History, Qom Branch , Islamic Azad University, Qom, Iran \\ ${ }^{3} \mathrm{Ph}$.D Student, Department of Public policymaking, Qom Branch, Islamic Azad University, Qom, \\ Iran
}

Dr.mahmoudpanahi@gmail.com

Keywords: Ethnicity, Public order, Geography of Iranian ethnic groups Globalization.

\begin{abstract}
Today, radicalism ethnocentrism has become a primary source of violent armed conflicts inside the country and in some parts of the world and has entailed an attrition of nation-state's power. On the other hand, ethnic nationalism in some countries has targeted national integrity and the very foundation of the society. This paper seeks to respond to the question: What impacts does this ethnic scatteredness and diversity have on the order and security of the Islamic Republic of Iran? What solutions are there for the national integrity? That which is certain is the existence of various ethnic groups in Iran which have rarely caused conflicts and engagements; from the issue of Turkmen Sahra and Azarbayjan in the early Revolution to the strikes by Kurdish people in May 2010 which are all issues that have been effective on the public order and security of Iran. Therefore, it is necessary for Iran to adopt effective steps in the direction of national integrity while relying on converging components of the Iranian ethnic groups including shared religion, shared land, and also the issue of shared security. Of course, looking upon the 37 year old history of Iran, this demonstrates that the country has made huge progress in this regard. The methodology is descriptive-analytical and by using data and information, some solutions have been offered.
\end{abstract}

\section{Introduction}

One of the concepts which have affected the ethnocentrism is "Globalization". Within the category of globalization, a kind of alienation on the one hand, and a difference on the other hand constitute the main network of thinking, and humans, while preserving identity and self-identity will find shared characteristics and insights where different insights behaviors and cultures will continue also. In the book " Globalization and disruption of international relations in the $20^{\text {th }}$ century" Ian Clark writes: "Global developments suggest that two processes of globalization and disruption occur simultaneously and world affairs will manifest a contradictory facet; for instance, in the 1990s, within the area of economy, the process of globalization predominated while in the field of politics, ethnic nationalism intensified [1].

Today, globalization is not simply considered a factor for homogenizing and assimilating because globalization does not oppose localization absolutely. Those two categories are closely related and are created by a single dynamism which is usually kown as the global term of localization. For Ronald Robertson, globalization always occurs in a local framework whereas at the same time, the local framework is by itself created through globalization discourse. His states globalization must not be simply regarded as a process which link pre-existing places. He prefers the global term of localization; because this term in its own definition denotes a global view which consider local conditions. Thus, dissimilation is always and persistently produced and reproduced through globalization processes [2]. 
In the early $20^{\text {th }}$ century social sciences scholars used to regard racial and linguistic identities and interest as a kind of retreat and historical abnormality which was either destroyed in the face of Communism or got incorporated within the frameworks of Liberal Democrat Institutions. The surviving ethnic group is thought of the initial stages if the human society development which will be lost sooner or later [3].

Ethnic conflicts and stand-offs are not exclusive to developing countries whatsoever. Basque secessionists in Spain, Italian dissidents in the south of Tyrol, Scottish nationalism tendencies and Welsh radicalism in the England, old violence inn northern Ireland, secessionist sentiments in the Quebec state of Canada, competitions between Valouns and Flemiaee in Belgium or continued racial conflicts in the United States of America demonstrates the role of ethic belongings as a source for creating conflicts and competition in large states of post-industrial democracies of the western Europe and northern America. The ever-increasing trend of ethnic conflicts is so huge that it has challenged political conflicts and geopolitical frameworks across the world.

In the Middle East, there re countries with ethnic diversity; its successful example is Lebanon that despite various ethnic groups, specially various relations, they have made progress in having a coexistent of together. Instead, of vulnerable ethnic diversity, we can name Afghanistan where biased ethnicity has brought bout numerous problems for this country.

\section{Theoretical framework}

As Buzan maintains, social threats cannot be separated from, political threats. For him, social threats occur when essentially the social security of a state is exposed to danger. Social security could be considered the ability of preservation and safety of traditional linguistic, cultural patterns as well as religious and national identity [4]. Social insecurity on the other hand occurs when any sort of community-national ethnic, religious and racial- defines a new development or arrangement as a threat against their own survival (social identity) [5]. He argues that national identity is often subjected to threats from the inside of a multi-ethnic country and the nation-state process is directed at silencing or at least assimilating quasi national social identities. Despite such challenges by infra national identities towards national cultural and social identity, Buzan maintains that social threats are among signs of a weak state and it cannot be regarded as a national security issue unless in cases it wages inter-state conflicts [5].

Although Buzan considers the category of social threats within the modality of solvable issues in advanced societies and remove from the realm of national security issues, the fact is in developing multi-ethnic societies not going through superior stages of nationalization and there are social gaps, sources of conflicts a $\mathrm{d}$ anti state activities, social threats could as much as political areas or even higher than that culminate in contradiction with the national security. It is on the same basis that Olive Wever, while criticizing Buzan has consider social security as beyond political, military and economic security and argues that the corresponding definition of social security is national security; because social security under current conditions is considered to be the national security source [5]. The other point is that social identity, according to its definition provided by Buzan has taken a political meaning from the social insecurity/. Accordingly, the reaction by a minority group in defense of its own identity is a political act per se; hence social security assumes importance in as much as the national security.

Besides two components of legitimacy and politicking competence Azar and Moon have considered the integrity crisis as the most important variables of national security across the third world. For them, social multiplicity and conversion of a multi-ethnic country or a nation-state will add new dimensions to the very complicated issue of national security in the third world of its most tangible index is the frustration of developing countries in building a shared public sense regarding their national shared values and interests. Existence of rooted gap, does not allow for the possibility of integrating shared national needs, values and interests in the past and any ethnic group creates of own special collective identity based on group values and interest instead of national interests [5]. Huntington and Weiner consider the role of social scattered structure as highly destructive ion the area of the government. They maintain that the social structure affects the status of politics at the 
highest levels of state up until the lowest ranked executives. The difference in priorities of state leaders, the extent to which state policies are ineffectively exercised, costly structure of the state's organization for exercising social control and fixing political order and stability and creating some false political and cultural unit and capturing areas of state's authorities by special groups are all originated from the scattered structure of the society [6].

\section{Definition of ethnicity and varied scope within the Iranian society}

Most researchers of the Mideast affairs including Iran have not rolled put any definition of ethnic groups in their own writings and they do not specify what determinant criteria are in their view; for instance, concerning works of some of the Iranian researchers which have been conducted over the issue of ethnicity and ethnic groups in Iran, no definitions have been offered in regard to ethnic groups or the determining criteria. Works by non-Iranian researchers also involve such problems. As stated Iranian authors also perceive that ethnicity and ethnic groups are defined as phenomena which are already known by the readership. Having said thus, though there is no specific definition of ethnicity which is agreed upon by most sociologists, all of whom agree that ethnicity involves such "Subjective" and "Objective" components; these components are: subjective interest and awareness of the identity, shared interests belonging, shared interest and objective cultural commonalities in language historical background, religion and shared land both currently and in the past [7]. Therefore,, it can be stated that to accurately and better understand the term "Ethnicity", considering subjective and objective components are imperative because one can thorough this outline as specific boundary for them and separate this term from other concepts.

For Yinger, when the following conditions are met, the concept of ethnicity will be fully clarified:

1. Some part of a large society is looked upon differently by other part of that society due to a combination of the following features like language, religion, race, ancestors' lands and the culture appertaining to it:

2. Members who consider themselves as possessing top conditions;

3. The participation of these members in shared activities based on the axis of origin and real or fiction culture.

Thus, ethnicity is not at all singular; rather they do exist in an ethnic system and existence of an ethnicity indicates their existence [7].

In Iran, various ethnic groups are residing; Lor, Balouch, Turkmen, Turks, Arabs, Kurds and Fars. Some Iranian ethnic groups are resident in border areas and have some religious and cultural bonds with other ethnic groups in the neighboring countries; for example, Baluch people in the southeastern parts in the border with Pakistan, Turkmen in the northeastern parts with Turkmenistan, Azari people in the north and northwestern parts of the country in neighborhood with the Republic of Azarbayjan and Turkey, Arabs in the west and southwest with Iraq and finally Kurds in the west and northwest of the country in proximity with Iraq and Turkey [8]. Therefore, one has to say that from a social structural standpoint Iran is a non-homogenous country wherein various racial, ethnic, linguistic and religious groups are residing and there are also various groups in neighboring countries. From a special studies standing, there are some centrifugal groups in Iran specifically in the periphery of borders that could be considered as focal points of crises. On other hand, corresponding ethnic groups in neighboring countries including Arabs and Kurdish in Iraq, Azari people in the Republic of Azarbayjan and Baluch in Pakistan could be regarded as factures for creating tensions and crises [9].

Meantime, this level of variation in Iran compared to other countries which are called multi-ethnic group is somehow indigenous. In other words, in most of the mentioned countries, diversity and plurality mostly originate from migration of ethnic groups from far and near countries. This means that diversity and variations Iran is mostly an endogenic category and assimilation of border dwelling ethnic groups with other ethnicities on the other side of the border could affect ethnic groups in the Iranian society. This level of endogen could be an opportunity for promotion of 
national coherence and integrity factor. Meanwhile, mentioned diversity and plurality indicates that the level of collective identity within Iranian society is mostly downgrading, smaller and peculiarity and general collective identity at the country's level and among ethnic groups is very weak.

\section{Ethnic groups and security}

Richard Schultz while classifying types of conflicts examine ethnic and religious conflicts within the low intensity conflicts framework and maintains that though examples of these conflicts are observed in the post-World War Two, experts consider as originating in the 1980s [10]. The most important reason why such conflicts are considered to be low intensity conflicts in the Shultz's classification was that the influence and security outcomes of such conflicts were limited to the geographical area of a country and finally, entail little regional implications. Thou it was possible for such conflicts to become genocides and national-religious cleansing as well as large scale human catastrophes, since it was not considered a danger directed at the security of superpowers and power Blocs, they were regarded as low intensity conflicts.

Large scale studies were conducted in the 1960s and 1970s where ethnic in most of which was examined as a form or source of violence and instability. Results appertaining to this group were impressive, As much as $70 \%$ of all the conflicts under study resulted from ethnic and nationalistic bias and partiality. Fifteen years later, i.e. in 1984, the same conflicts were analyzed and it became clear that thirty cases of which had once led to intense internal strife [11]. Ted Robert Gurr, in response to the issue of when an ethnic identity leads to some political Basij and action and thus converts to a security variable states that when an ethnic group is subjected to threats or aggression by some other groups or states in various ways, one has to expect an ethnic movement. Thus, for him, most ethnic movements emerged in the final decades of the $20^{\text {th }}$ century in response to the threats by political settings like rejection or racial segregation. Social constructivist approach too considers threatening change of social and political and environmental requirements as a basis for the Political Basij and action of ethnic identities against state's ethnic approaches and polices. In this way, the issue of ethnicity has become a political and security issue fir the state [12].

Ethnic related political threats, in addition to deep effects on the state-society affected and relations as well as formation of special state patterns could be directed at undermining of political legitimacy and ineffectiveness of the government with regard to large scale political Basij, demonopolization of violence and undermining prevalent national identity. Regarding the role of ethnic diversity is the emergence of crisis within the national identity, Lucian Pie argues that this crisis occurs when the government, due to the fact that major elements of the country population are more obliged to infra national groupings cannot play roles as an effective national unit. In other words, nation-states' tasks cannot b satisfactorily executed because of lack of support for a strong sentiment [6]. Anthony Smith also considers ethnocentrism as a de-integrating factor within the area of identity a d national power. For him, ethnic conscience which seeks its identity in the shared blood, shared race and common religious and linguistic features calls for myths and historical memories; this will totally bring about a consequence whose result is formation of an ethnic identity and reinforcement of solidarity and ethnic coherence against some national and comprehensive identity. This consequence is politically a force which is directed at the independent power and state and culturally speaking, it seeks to formalize its own cultural and ethnic values [13].

Ethnocentrism and security are associated with one another in two national and supranational levels and this link has caused social and political analysts to work on ethnic situations more than ever before such that review of history a d pathology of Iran's internal security could pave then ground for boosting of stability inside and outside of the country. Since ethnocentrism is one of the major indices in understanding the natural capacity of countries for attaining stability and distance from violence, security of countries wont' take place without paying attention to this. In the Islamic Republic of Iran, it appears that this subject, given plurality of ethnic groups a $d$ their historical background will be raised [14]. In an overall classification, factors that would engender in ethnic unrest could be examining fewer than five political, economic, social, cultural and psychological factors. 
Political factor: what is true is that the attempts by the central government for cultural integration and expansion of nationalism thinking among various ethnic groups of a country on the one hand and loss of official power canals for resolving ethnic oriented demands peacefully, nonestablishment of a citizenship system and civil society or a political system based on democracy, plurality and federalism on the other hand, are all factors effective in aggravation of ethnic sentiments and emergence of independence seeking violence, Decline of political power of the governance board due to emergence of various factors or placement in the transition stage of a developing society could lead to such violence. In this connection, role of foreign powders, specifically colonial countries which try to create crises for preserving their own dominance must also be taken into account [15].

Economic factor: Economic pressure resulting from balance in economic expansion of different areas and mismatch of facilities a $d$ amenities provided by the central government among various ethnic groups are among major elements that would challenge the relations of this groups and the central government [15].

Social factor: Emergence of protesting movements among ethnic and racial groups is usually resulting of economic and social deprivations; Existence of stimulating -often leftist- ideologies by popular leaders could culminate in protest movements among various ethnic groups [15].

Cultural factor: Disruption in the acculturation trend and resistance against cultural integration which often seek attempts by the central government for cultural assimilation in a community and among various ethnic groups that would lead to advent of ":Surplus value and cultural transaction" are among major factors resulting in the emergence of ethnic tension and Basij.

Psychological factor: Psychological and mental characteristics of "ethnic masses" are the most significant elements of psychosocial examinations and mental characteristics of ethnic groups' elites are thought of the most important elements for individual psychology examinations. "Frustration" that can be deemed as result of such factors as dissatisfaction of mental and essential needs, failures and relative deprivation sentiment and "prejudice" which is result of old hostility and stereotypical perceptions arising from traditions, customs and conventions as well as cognitive incoordination or dissimilation, revers perceptions all play major roles in intensifying ethnocentrisms sentiments.

\section{Factors effective in convergence of Iranian ethnic groups}

1. Language and culture: Essentially, the language of any nation is thought of main pillars of the culture and indicative of the culture if each nation. Culture relying on language constitutes cultural identity and personality of each nation. If people of France are called French, not only due to language rather because of culture being a fundamental factors comprising their national identity are called French,

2. Customs and social traditions: Social traditions and customs of each nation, in addition to reflection and process of that nation's functions constitute the most significant elements that specify national identity of that nation;

3. Religion: In most countries, the religion factor, in addition to specification of cultural and religious identity of that country are among the identification elements of that country across the world and are sometimes known as major elements of national solidarity. However, it should be mentioned that given most religions are not specific to the people of a country, hence social science experts currently consider religion as a spiritual factor and benefit from the very primary elements for the national identity.

4. Race factor: in the past, this factor was considered as a primary factor for solidarity and identity among primitive ethnic groups and groups in the medieval centuries. However currently, with the expansion of communications and large information among states in the international arena, it has lost some of its significance.

5. Shared land: gathering of people in a shared land is known as the primary factor for the solidarity of a state. People living in a shared land will find some linguistic and cultural solidarity together. The speech by Hans Cohen, the America sociologist and nationalist politician is interesting in this regard. He states: "Political boundaries result in creation of 
nations". For example, the nation of Canada which is created of the combination of two completely distinct nations is a resultant of political and geographical unity of that country.

6. Economic factor: Of economic factors for building national solidarity is the economic factor in a manner that the role of this factor is more significant than other factors, because in most cases it has been witnessed that people have been different from each other in terms of language culture race and religion but economically, they have had a shared goal and as a result of collaboration together they have been intertwined in each other, Switzerland is one of these countries.

\section{Ethnic policies in relation with public security}

a) Assimilation paradigm

The term assimilation, according to the simplest definition is a process wherein people of different characteristics are assimilated together. In a paper in 1901, Simons defined this term as follows: "The process of adaptation or compatibility which occurs among members belonging to two different races and is a result of group based homogeneity or homosexuality" [16]. On some occasions, assimilation is exercised with violence so that people of a minority groups under such pressures accommodate themselves with the majority group. Destruction or culling is assimilation along with violence and it is a process in which members of a minority group are manslaughter at the hand of majority group. When this process is done against a minority ethnic group it is called genocide [17].

In the Pahlavi era Iran, the policy of assimilation was implemented fully and systematically from the time of Reza Shah. Reza Shah's dominance along with the inculcation if radical nationalism arising from the idea of "Superiority of Arya race" created some problems for many of the Iranian minorities. From the standpoint of Reza Shah and his respective state, a strong and modern state means a negation of cultural plurality in the country. For him, all the society apart from cultural, linguistic and ethnic plurality should have spoken one language, and been attributed to one single culture. Persian language was converted to the standard language of the county and the history and culture of Persian speaking people became the sole source of Iranian identity. All the Iranian s living within the Iranian realm were banned from wearing ethnic and local clothes and writing and printing their own language and any other Non-Persian manifestations and the violators were punished. Thus, Iran was known a s country with one language and culture [7].

Mohamad Reza Shah, too followed his father's policy against ethnic groups. In his tenure, the government possessed the highest threshold of suppression and since his government's power was great, no ethnic group was allowed to have activities and hence the government used to pummel and breach their legitimate and legal wants within the pretext of assimilation format. In his era, too publication and distribution of papers, journals and books in ethnic languages were highly prohibited. Even the names of shops and grading firms in ethnic locations could not be written in ethnic languages. Ethnic elites were deprived of civil rights of press freedom and freedom of expression and of gathering in all provinces were established and security police used to control peoples traffic [18].

\section{b) Pluralism paradigm}

From a general perspective, pluralism is the opposite of assimilation. Pluralism, like assimilation involves different forms and dimensions; however, in all of its cases, preservation or aggravation of differences between ethnic groups have been hypothesized; thus, policies designed for supporting pluralism encourage group diversity a d preservation of borders separating ethnic groups from each other. Unlike assimilative policies, pluralism policies are founded on the principle of "collective and group rights" other than "personal and individual rights".

In a plural and democratic system, there is no way but to equal and balanced distribution of opportunities, facilities and capital in the country and through this, one can pave the ground for sustainable development in the country. Attention to growth and development of ethnic regions' 
economies, while entailing help to national development could be effective in increasing inter regional social and economic dependency and solidarity resulting from these factors [16]. One of the fundamental ways for prohibition from formation of ethnic crisis is to apply pluralism policies, partially cultural pluralism against ethnic groups. Respect for customs of ethnic groups and subcultures, authenticity of cultural and ethnic diversity and attention to the principle of unit could pave the way for many of the problems. This means that the national unity and coherence of the country is possible in case the principle of existing divest is accepted. Under such conditions, the natural and historical competence of the nation needs to be preserved and continued through time.

The concrete example of pluralism policy in Iran could be seen in the early revolution, expansion of the range of political freedom in one and half years after the victory of the Islamic Revolution allowed for the emergence of various political tendencies to people and different groups of people. However, unfortunately due to violent demands on the part of some groups defending civil rights resulted, in ethnic conflicts. The Isla ci Republic of Iran which was faced with the ethnic group conflicts adopted the special economic, social and cultural policies which involved contradictory effects [7].

Upon little reflection and attention to the Constitution and Exclusive Principles regarding removal of deprivation and segregation from ethnic groups, it can be easily perceived that the Islamic Republic of Iran's Constitution possesses extraordinary capacity to attain superior goals and provide fundamental rights of all Iranians specifically religious and ethnic groups.

Principle 19 of the Constitution states explicitly that "Iranian people of any clan or tribe enjoy equal rights, and color, race, language and the like won't divest them from these rights

Principle 20 of the Constitution states explicitly all people of the nation including women and men are equal in the ye of the laws and they all enjoy all human, political economic, social and cultural rights in accordance with the Islamic Laws

Principles 15, while introducing Persian writing and language as the formal and standard language of the country has announced using local and ethnic languages in mass media and press as well as their teaching in schools along with Persian free.

Principle 12, while introducing the official religion of the country has placed respect for all other religions and recognized their followers.

Principle 13 of the Constitution recognizes the same freedoms-conduct of rituals and religious ceremonies and personal status- for Jewish, Christian Iranians.

Principle 14 obliges the Islamic Republic of Iran, Iran and Iranians to dal non-Muslims in good will and in accordance with Islamic Justices and respect their human rights [19].

\section{Conclusion}

Given the main question: What impacts does the ethnic scatteredness and diversity have on the order and security of the Islamic Republic of Iran? And also in line with the main hypothesis test which was "existence of various ethnic groups in Iran resulted in many conflicts and security problems", after testing the question, some thematic results, scientific advices and also some practical guidelines are stated as following:

- A country with ethnic diversity may get its national security endangered with any sort of conflicts and wars or independent movements; hence the duty of the state is to create unity and solidarity in the society. Iran is among countries which have ethnic plurality; Iran's neighbors (Turkey, Iraq, Syria and Kuwait etc.) are among the countries which in terms of ethnicity of Turks, Kurds and Arabs have reciprocal influence among ethnic groups inside Iran. This existence of any sort of conflicts a d independence movement might stimulate the and stir these ethnic groups and hence they could be considered as threats against national security. Iran as a country with some sectarian and ethnic diversity has always been exposed to threats by the opponents o the Islamic Republic of Iran 
- Focus attention to ethic issues is one of the effective indices in the results of different elections; for instance, during the Presidential Elections in 2013, attention to demands and claims of ethnic groups and different religious sects were greater. Mr. Rouhani who could assume office with majority vote of Iranian placed emphasis on using elites apart from language, religion and ethnicity within managerial posts in different areas of the country, teaching mother tongue at academic levels. Reinforcing ethnic literature and culture, respecting religious rights and non-interfering with their religious affairs. This approach was welcomed by most Iranians, particularly religious ethnic groups and minorities. Examination of geographical participation of people in the $11^{\text {th }}$ period of elections indicated that $\mathrm{Mr}$. Rouhani managed to acquire 770, 000 votes in Sistan and Baluchistan and 438, 000 votes in Kurdistan where the vote rate was quite significant.

- In the end, we can say that ethnicity and ethnic nationalism could today like geopolitics variables and strategic sources like oil and international setting indicate fundamental issues specifically national security and public security of the multi-ethnic societies. In this area, the other issue which is of significance is the necessity of formulating citizenship's rights. It sounds that the low cost and rational way for providing groups of p3ople within the framework of establishing and providing citizenship rights can be achieved.

\section{References}

[1] F. Ghoreishi, Globalization-writing and assessment of different interperration. Foreign policy quarterly, vol. 14, pp. 37-45, 2000.

[2] K. Nash, Contemporary sociologist Tr. by Taghi Delforouz. Tehran: Kavir publication, 2001.

[3] A. Gol Mohamadi, Globalization of culture, Identity. Tehran: Nei publication, 2003.

[4] M. Castells, Age of information. Advent of networked society. Tehran: Tarhe Naw publication, 2001.

[5] B. Buzan, People, states and Fear. Tehran: Strategic Studies Faculty, 1999.

[6] E. Azar, National security in the third world. Tehran: Strategic Studies Faculty, 2000.

[7] A. Ramazan Zade, Expansion and ethnic challenges. Public development and security, vol. 2, pp. 231-249, 1996.

[8] H. R. Jalaeepur, Kurdistan: Causes of continuation of crisis after the Islamic revolution. Tehran: Ministry of foreign affairs institute. 1996.

[9] G. Fowler, World's focus, Tr. by Abbas Mokhber. Tehran: Markaz publication, 1993.

[10] M. Ballmer and J. Solomoz, Ethnic and racial studies in the $20^{\text {th }}$ century, Tr. by Parviz Dalir Parvar and Seyed Mohamad Kamal Sarvarian, Tehran: Strategic Studies Faculty, 2002.

[11] A. Eftekhari, Natural capacity of security. Tehran: Strategic Studies Faculty, vol. 5, pp. 121$134,2000$.

[12] R. Ted Gurr, People versus state: minorities at risk in the new century. Untied States: Institute of peace process, 2000.

[13] L. Pie, Crisis and sequences in political expansion, Gholam Reza Khaje Sarvari. Tehran: Strategic Studies Faculty, 2001.

[14] A. Eftekhari, Violence and society. Tehran: Safir publication, 2000.

[15] M. Maghsoudi, Grounds for emergence of ethnic crisis in ran after the victory for the Islamic revolution, 2000.

[16] S. R. Salehi Amiri, Management of ethnic conflicts in Iran. Tehran: Strategic research center of the expediency council, 2008.

[17] G. A. Tavasoli, Basics of sociology. Tehran: SAMT publication, 1995.

[18] H. Amir Ahmadi, Ethnocentrism and security, Tr. BY Hasan Shafiei. Strategic Studies Faculty, vol. 2, pp. 219-230, 1998.

[19] A. Zahedi, Iranian Constitution. Tehran: bungle Javabe publication, 2015. 